\title{
TRANSFORMATION METHODS FOR USING COMBINATION OF REMOTELY SENSED DATA AND CADASTRAL MAPS
}

\author{
Ş. Ö. Dönmez ${ }^{\text {a }}$ A. Tunc ${ }^{\text {a, * }}$ \\ a ITU, Civil Engineering Faculty, 80626 Maslak Istanbul, Turkey - (donmezsaz, tuncali1)@itu.edu.tr
}

KEY WORDS: transformation methods, aerial orthophotos, cadastral maps

\begin{abstract}
:
In order to examine using cadastral maps as base maps for aerial orthophotos, two different 2D transformation methods were applied between various coordinate systems. Study area was chosen from Kagithane district in Istanbul. The used data is an orthophoto (30 $\mathrm{cm}$ spatial resolution), and cadastral map (1:1000) taken from land office, containing the same region. Transformation methods are chosen as; $1^{\text {st }}$ Order Polynomial Transformation and Helmert 2D Transformation within this study. The test points, used to determine the coefficients between the datums, were 26 common traverse points and the check points, used to compare the transformed coordinates to reliable true coordinates, were 10 common block corners. The transformation methods were applied using Matlab software. After applying the methods, residuals were calculated and compared between each transformation method in order to use cadastral maps as reliable vector data.
\end{abstract}

\section{INTRODUCTION}

Modern mathematics characterizes transformations in terms of the geometric properties that are preserved when the transformations are applied to features. For mapping, analysis, and georeferencing purposes we usually value one particular set of properties over all others: area when computing areas, orientation when computing directions, distance when computing distances, (local) angles when computing angles, similarity when comparing shapes, incidence and inside versus outside when performing topological comparisons, and so on. In each case there is a group of invertible transformations of the plane that preserves the desired properties. As surveyors we practise our engineering analyses in alternative coordinate systems. So in most cases, like every map and GIS user, we use 2D and 3D coordinate transformations. In this research $2 \mathrm{D}$ coordinate transformation procedures for $1^{\text {st }}$ degree Polynomial Transformation and Helmert Transformation are implemented to compare cadastral map coordinates of the 10 check points of two block corners.

A polynomial transformation is a non-linear transformation and relates 2D Cartesian coordinate systems through a translation, a rotation and a variable scale change. The transformation function can have infinite number of terms (Knippers, 2009).

Calculation of transformation parameters between aerial orthophoto and cadastral map coordinates using first order polynomial transformation can represent in mathematically as follows.

$$
\begin{aligned}
& X n=a_{1} X_{0}+a_{2} Y_{0}+a_{3} \\
& Y n=a_{4} X o+a_{5} Y_{0}+a_{6} \\
& X o-X \text { coordinates of aerial orthophoto } \\
& \text { Yo }-Y \text { coordinates of aerial orthophoto } \\
& X n-X \text { coordinates of cadastral map }
\end{aligned}
$$

\section{$\mathrm{Xn}-\mathrm{X}$ coordinates of cadastral map}

a1, a2, a3, a4, a5 and a6 are unknown parameters.

2D Helmert transformation is a special case that is only needed 4 parameters (two translations, one scaling, one rotation). It is needed at least two known points (X, Y), If there is more than two known points, it is needed to apply adjustment operations, and check points can be used for accuracy calculations.

The other name of this transformation method is similarity transformation. In this transformation, figures preserve own shapes which means angles between lines does not change. The edges of the smooth geometric shapes grow or shrink at the same rate.

First system coordinates (given): $\mathrm{x}_{0}, \mathrm{y}_{\mathrm{o}}$;

Second system (transformed) coordinates: $\mathrm{x}_{\mathrm{n}}, \mathrm{y}_{\mathrm{n}}$;

$\mathrm{k}_{01}, \mathrm{k}_{02}$ : displacement parameters

$\phi$ : rotation angle; angle between $\mathrm{x}$ 'and $\mathrm{x} ; \mathrm{y}$ ' and $\mathrm{y}$.

$\lambda$ : scale;

$\mathrm{x}_{\mathrm{o}} \rightarrow \lambda \mathrm{x}_{\mathrm{o}}, \mathrm{y}_{\mathrm{o}} \rightarrow \lambda \mathrm{y}_{\mathrm{o}}$

A sample of graphic representation of the systems is shown in Figure 1 below.

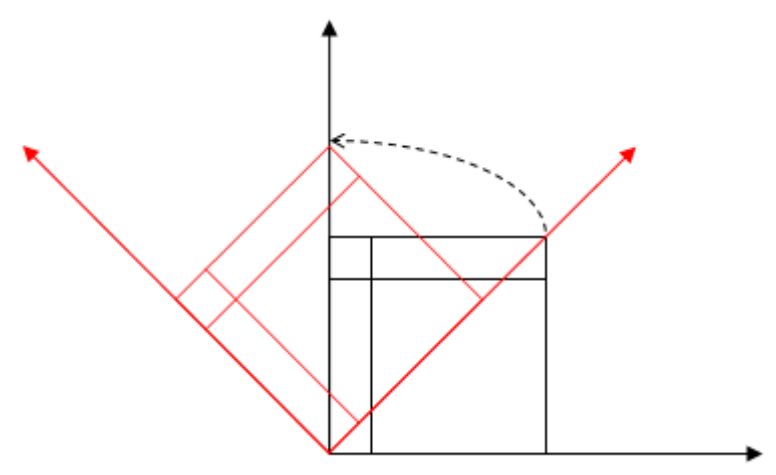

Figure 1. Graphic representation of 2D Helmert transformation

General formula is shown: 
$\mathrm{x}_{\mathrm{n}}=\mathrm{k}_{01}+\lambda \mathrm{x}_{\mathrm{o}} \cos \phi-\lambda \mathrm{y}_{\mathrm{o}} \sin \phi$ $\mathrm{y}_{\mathrm{n}}=\mathrm{k}_{02}+\lambda \mathrm{x}_{\mathrm{o}} \sin \phi-\lambda \mathrm{y}_{\mathrm{o}} \cos \phi$

$\mathrm{k}_{01}, \mathrm{k}_{02}, \lambda, \phi$ are translation parameters. These equations; with translation of $\mathrm{k} 11=\lambda \cos \phi \quad \mathrm{k} 11=\lambda \sin \phi$;

$\mathrm{x}_{\mathrm{i}}{ }^{\prime}=\mathrm{k}_{01}+\mathrm{xi}_{11}-\mathrm{y}_{\mathrm{i}} \mathrm{k}_{12}$

$\mathrm{yi}^{\prime}=\mathrm{k}_{02}+\mathrm{yi}_{\mathrm{i}} \mathrm{k}_{11}+\mathrm{xi}_{\mathrm{i}} \mathrm{k}_{12}$; and scale factor $(\lambda), \phi$ are calculated as; $\lambda=\sqrt{(k 11)^{2}+(k 12)^{2}}$

$\phi=\arctan \frac{k 12}{k 11} \quad($ Demirel, H. $)$

\section{DATA SET}

The used data is an orthophoto (30 $\mathrm{cm}$ spatial resolution), and cadastral map (1:1000) taken from land office, containing the same region.

The test points, used to determine the coefficients between the datums, were 26 common traverse points; the check points, used to compare the transformed coordinates to reliable true coordinates, were 10 common block corners.

\begin{tabular}{|c|c|c|}
\hline \multirow{2}{*}{$\begin{array}{c}\text { Point } \\
\text { I.D. }\end{array}$} & \multicolumn{2}{|c|}{$\begin{array}{c}\text { Aerial Orthophoto Traverse Point } \\
\text { Coordinates }\end{array}$} \\
\cline { 2 - 3 } (ITRF96)
\end{tabular}

Table 1. Aerial orthophoto traverse point coordinates (ITRF96)

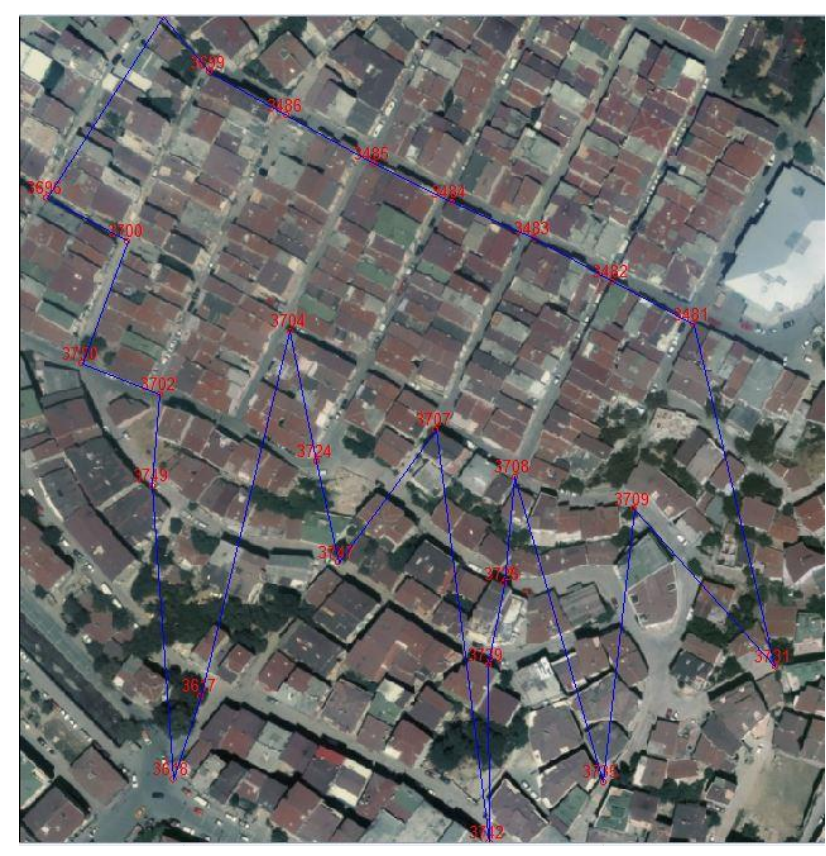

Figure 2. Aerial orthophoto test point representation

\begin{tabular}{|c|c|c|}
\hline \multirow{2}{*}{\begin{tabular}{c}
\multirow{2}{*}{$\begin{array}{c}\text { Point } \\
\text { I.D. }\end{array}$} \\
\cline { 2 - 3 }
\end{tabular}} & $\begin{array}{c}\text { Cadastral Map Traverse Point Coordinates } \\
\text { (ED-50) }\end{array}$ \\
\hline $\mathbf{3 4 8 1}$ & 11051.470 & Yn (m) \\
\hline $\mathbf{3 4 8 2}$ & 11066.210 & -6637.240 \\
\hline $\mathbf{3 4 8 3}$ & 11081.390 & -6666.450 \\
\hline $\mathbf{3 4 8 4}$ & 11093.980 & -6694.540 \\
\hline $\mathbf{3 4 8 5}$ & 11107.360 & -6724.410 \\
\hline $\mathbf{3 4 8 6}$ & 11124.460 & -6752.350 \\
\hline $\mathbf{3 6 1 7}$ & 10916.480 & -6783.830 \\
\hline $\mathbf{3 6 1 8}$ & 10886.700 & -6812.210 \\
\hline $\mathbf{3 6 9 6}$ & 11093.790 & -6821.750 \\
\hline $\mathbf{3 6 9 8}$ & 11159.040 & -6869.450 \\
\hline $\mathbf{3 6 9 9}$ & 11139.530 & -6828.510 \\
\hline $\mathbf{3 7 0 0}$ & 11078.620 & -6811.710 \\
\hline $\mathbf{3 7 0 2}$ & 11024.010 & -6840.370 \\
\hline $\mathbf{3 7 0 4}$ & 11047.210 & -6828.060 \\
\hline $\mathbf{3 7 0 7}$ & 11012.650 & -6781.730 \\
\hline $\mathbf{3 7 0 8}$ & 10996.140 & -6729.130 \\
\hline $\mathbf{3 7 0 9}$ & 10985.090 & -6700.620 \\
\hline $\mathbf{3 7 2 4}$ & 11000.860 & -6657.770 \\
\hline $\mathbf{3 7 2 6}$ & 10957.940 & -6771.650 \\
\hline $\mathbf{3 7 3 1}$ & 10929.410 & -6704.070 \\
\hline $\mathbf{3 7 3 5}$ & 10887.430 & -6606.650 \\
\hline $\mathbf{3 7 3 9}$ & 10928.690 & -6667.680 \\
\hline $\mathbf{3 7 4 2}$ & 10865.330 & -6709.390 \\
\hline $\mathbf{3 7 4 7}$ & 10964.850 & -6708.250 \\
\hline $\mathbf{3 7 4 9}$ & 10991.380 & -6763.440 \\
\hline $\mathbf{3 7 5 0}$ & 11034.920 & -6830.450 \\
\hline & & -6856.210 \\
\hline
\end{tabular}

Table 2. Cadastral map traverse point coordinates (ED50) 


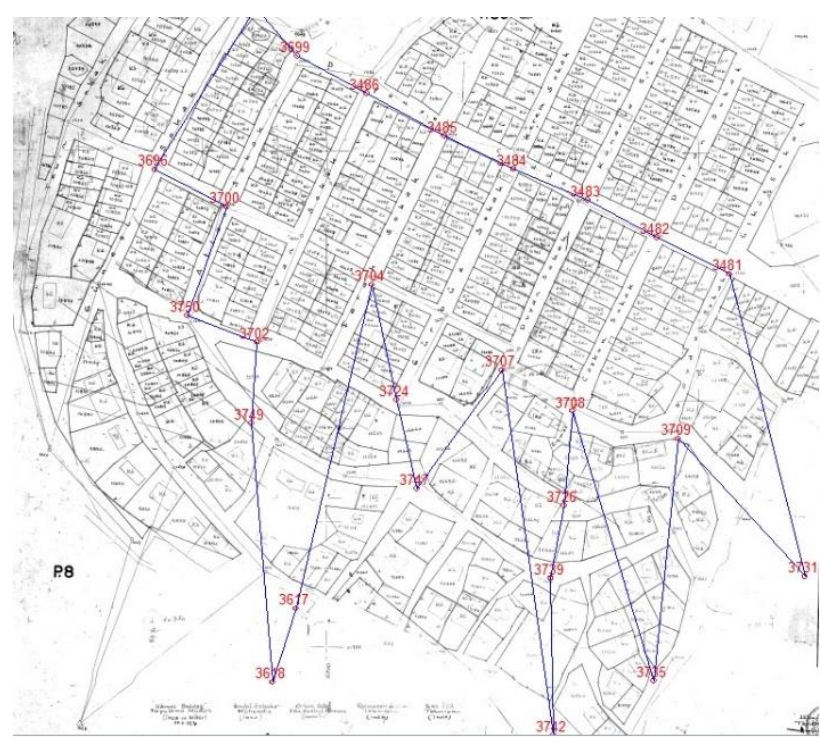

Figure 3. Cadastral map test point representation

\section{APPLICATION}

After applying the $1^{\text {st }}$ order Polynomial transformation and 2D Helmert transformation methods, the transformation coefficients calculated using Matlab software.

\begin{tabular}{|c|c|}
\hline Parameter & Approximated Value (1 ${ }^{\text {st }}$ order Polynomial) \\
\hline $\mathbf{a}_{1}$ & 0.999830533153803 \\
\hline $\mathbf{a}_{2}$ & 0.011687641358797 \\
\hline $\mathbf{a} 3$ & -0.000000000106766 \\
\hline $\mathbf{a} 4$ & -0.011686688064981 \\
\hline $\mathbf{a} 5$ & 0.999830239688893 \\
\hline $\mathbf{a} 6$ & -0.000000000091252 \\
\hline
\end{tabular}

\begin{tabular}{|c|c|}
\hline Parameter & Approximated Value (2D Helmert) \\
\hline $\mathbf{k}_{\mathbf{0 1}}$ & $-4542989,16636722$ \\
\hline $\mathbf{k}_{\mathbf{0 2}}$ & $-368541,351771835$ \\
\hline $\mathbf{k}_{11}$ & 0,999830254761944 \\
\hline $\mathbf{k}_{12}$ & $-0,0116870608244562$ \\
\hline
\end{tabular}

Table 4. Calculated transformation coefficients for $1^{\text {st }}$ Order polynomial and Helmert transformation

The least square method used to calculate the coordinates of the block corners to compare them with the reliable aerial orthophoto coordinates. To do such residuals calculated in order to determine using cadastral maps as base maps.

After extracting the obtained coordinates from the aerial orthophoto coordinates of the block corners both transformation method gives a reliable accuracy for using cadastral sheets for base maps.

\begin{tabular}{|c|c|c|}
\hline \multirow{2}{*}{ Point ID } & \multicolumn{2}{|c|}{$\mathbf{1}^{\text {st }}$ order Polynomial Transformation } \\
\cline { 2 - 3 } & Residuals in Xn $(\mathbf{m})$ & Residuals in Yn (m) \\
\hline $\mathbf{1}$ & -0.061113 & 0.153939 \\
\hline $\mathbf{2}$ & -0.934553 & 3.009963 \\
\hline $\mathbf{3}$ & -2.612569 & 1.784752 \\
\hline $\mathbf{4}$ & -1.677428 & 0.169056 \\
\hline $\mathbf{5}$ & -0.165847 & 0.840253 \\
\hline $\mathbf{6}$ & -0.688147 & 1.729389 \\
\hline
\end{tabular}

\begin{tabular}{|c|c|c|}
\hline $\mathbf{7}$ & -0.849622 & 1.740335 \\
\hline $\mathbf{8}$ & -1.482626 & 2.932406 \\
\hline $\mathbf{9}$ & -2.625343 & 2.837968 \\
\hline $\mathbf{1 0}$ & 0.546605 & -0.720273 \\
\hline
\end{tabular}

Table 5. Residuals for $1^{\text {st }}$ order Polynomial Transformation

\begin{tabular}{|c|c|c|}
\hline \multirow{2}{*}{ Point ID } & \multicolumn{2}{|c|}{ 2D Helmert Transformation } \\
\cline { 2 - 3 } & Residuals in Xn (m) & Residuals in Yn (m) \\
\hline $\mathbf{1}$ & $-0,061035$ & 0,153953 \\
\hline $\mathbf{2}$ & $-0,934487$ & 3,009981 \\
\hline $\mathbf{3}$ & $-2,612468$ & 1,784793 \\
\hline $\mathbf{4}$ & $-1,677315$ & 0,169093 \\
\hline $\mathbf{5}$ & $-0,165830$ & 0,840255 \\
\hline $\mathbf{6}$ & $-0,688134$ & 1,729394 \\
\hline $\mathbf{7}$ & $-0,849611$ & 1,740340 \\
\hline $\mathbf{8}$ & $-1,482620$ & 2,932414 \\
\hline $\mathbf{9}$ & $-2,625306$ & 2,837996 \\
\hline $\mathbf{1 0}$ & 0,546654 & $-0,720251$ \\
\hline
\end{tabular}

Table 6. Residuals for 2D Helmert Transformation

\section{RESULTS}

As known, field measurements and remotely sensed images as well are used for calculating coordinates for logically defined datums and systems. The coordinates of the image or cadastral datas does not have only one standard or unique coordinate system, they are usually needed to be transformed with operations. These transformation methods describe a new surface and new system with different origins and dimensions.

In this paper, 2D transformations are discussed with some perspectives. These transformations types were; 2D Helmert transformation and $1^{\text {st }}$ order Polynomial transformation. For both, same data (control and check points) are used, certainly different transformed coordinates are obtained. When the residual values are focused on, it can be easily compared the diagnostic test mathematically. In this stage, number of transformation parameters are another important issue for comparing and deciding convenient method.

According to study, these two transformation methods results show that, cadastral maps can be used reliably as a base map with integrating cadastral maps with using of such types of transformation methods. Another several transform methods and comparison of them are aimed to study for the future researches.

\section{REFERENCES}

Knippers, R.A. and Hendrikse J. Coordinate Transformations, Kartografisch Tijdschrigt, KernKatern 2000-3, 2001.

Karunaratne, F.L. Finding Out Transformation parameters and Evaluation of New Coordinate system in Sri Lanka, 2007.

Zaletnyik, P. Coordinate Transformation with Neural Networks with Polynomials in Hungary.

Demirel, H. Dengeleme Hesabı , Yıldız Technical University, 2009 